\title{
Exploring arsenic and other geogenic groundwater contaminants in the vast and scarcely studied Amazon Basin
}

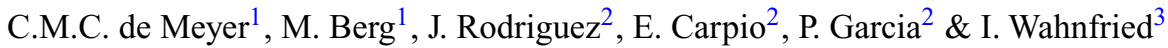 \\ ${ }^{1}$ Eawag, Swiss Federal Institute of Aquatic Science and Technology, Dübendorf, Switzerland \\ ${ }^{2}$ UNI, Universidad Nacional de Ingeniería, Lima, Peru \\ ${ }^{3}$ UFAM, Universidade Federal do Amazonas, Manaus, Brazil
}

\begin{abstract}
We conducted groundwater surveys in the Amazon Basin to determine the occurrence and distribution of arsenic and other contaminants. Initial results indicate that in groundwater resources in the recent floodplains of the Amazon River and of other white-water rivers, arsenic concentrations are often above the WHO-guideline value of $10 \mu \mathrm{g} \mathrm{L}^{-1}$ for drinking water. We compared the chemical analyses with geospatial data to identify vulnerable areas in the whole region. Understanding the regional geochemical mechanism(s) triggering the enrichment of arsenic in groundwater is important to raise awareness and implement mitigation where needed.
\end{abstract}

\section{INTRODUCTION}

To date, the groundwater quality in the Amazon region is very poorly known. This is of particular concern because people in both rural and urban areas rely on groundwater as their source of drinking water.

The Amazon Basin covers a vast region with heterogeneous geological and geographical features. In the floodplains of the Amazon river, and some of its main tributaries, high loads of Andean sediments get buried together with fresh organic matter. In those areas, reducing conditions in the subsurface are to be expected. The question remains if, where, and to what extend this may lead to reductive dissolution of arsenic and other redox sensitive elements in groundwater in concentrations harmful for human health. We seek answers to these questions by combining local scale groundwater surveys in selected areas of the Amazon Basin, with predictions on a regional scale using geospatial data.

\section{METHODS}

We sampled groundwater from domestic and community wells in the Peruvian Amazon (see Fig. 1). We chose the locations to be able to study groundwater from various depositional environments. In addition to

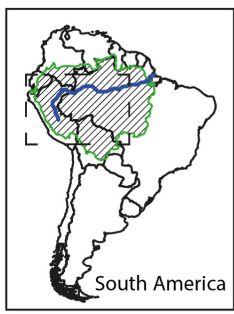

DV Amazon watershed

$\sim$ Amazon river

0 - 200 m.a.s.l.

200 - 7000 m.a.s.l.
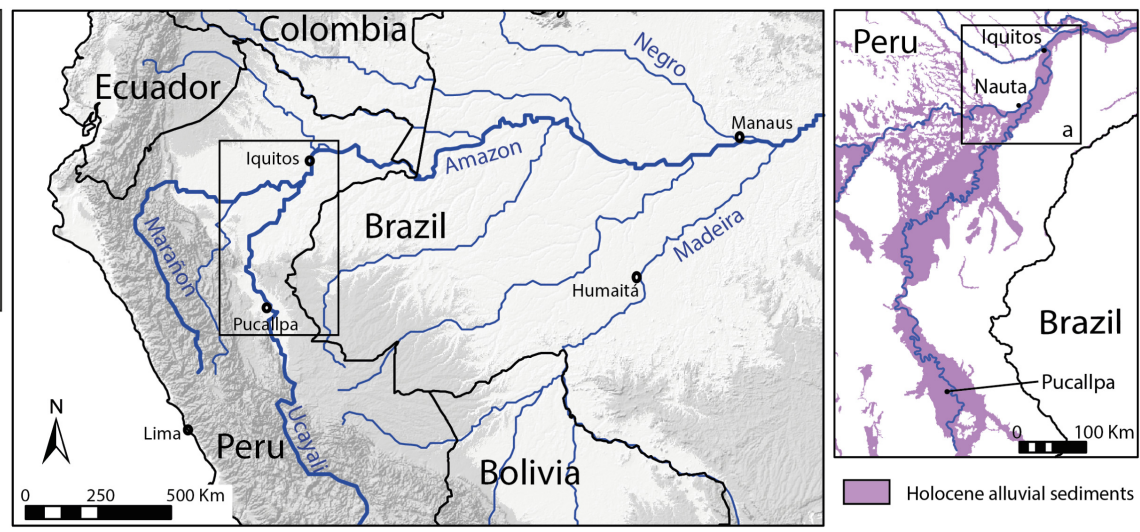

Figure 1. Location of the studied areas in the Western Amazon in Peru. Reducing subsurface conditions, and hence arsenic contaminated groundwater, is expected in the Holocene alluvial deposits along the Amazon River and some of its' main tributaries. Adapted from de Meyer et al. (2017). 
arsenic we analyzed some 50 groundwater parameters including major and minor elements.

We linked the groundwater data to environmental factors such as geology, topography, river geomorphology and soil, with the aim to develop a predictive map on the distribution of arsenic contamination on the sub-continental scale (Bretzler et al., 2017, RodriguezLado et al., 2013).

\section{RESULTS AND DISCUSSION}

\subsection{Groundwater survey}

Groundwater arsenic concentrations exceeded the WHO-limit of $10 \mu \mathrm{g} \mathrm{L}^{-1}$ (WHO, 2011) in a considerable amount of wells. Maximum values up to $700 \mu \mathrm{g} \mathrm{L}^{-1}$ were determined. High As-groundwater is of the $\mathrm{Ca}-\mathrm{Mg}-\mathrm{HCO}_{3}$ type, has a negative redox potential, slightly acidic $\mathrm{pH}$ and elevated concentrations of $\mathrm{Fe}, \mathrm{Mn}$, dissolved organic carbon, phosphate and ammonium (de Meyer et al., 2017). Based on these hydrochemical characteristics we concluded that arsenic is likely released by reductive dissolution of Fe-(hydr)oxides.

\subsection{Distribution of arsenic geogenic contamination}

de Meyer et al. (2017) observed that the distribution of arsenic in groundwater is linked to the depositional environment of the aquifer sediments. The contaminated wells tap groundwater from young alluvial deposits along the Amazon river and its main tributaries, as illustrated in Figure 2. These so-called white water rivers originate in the Andes and carry a high

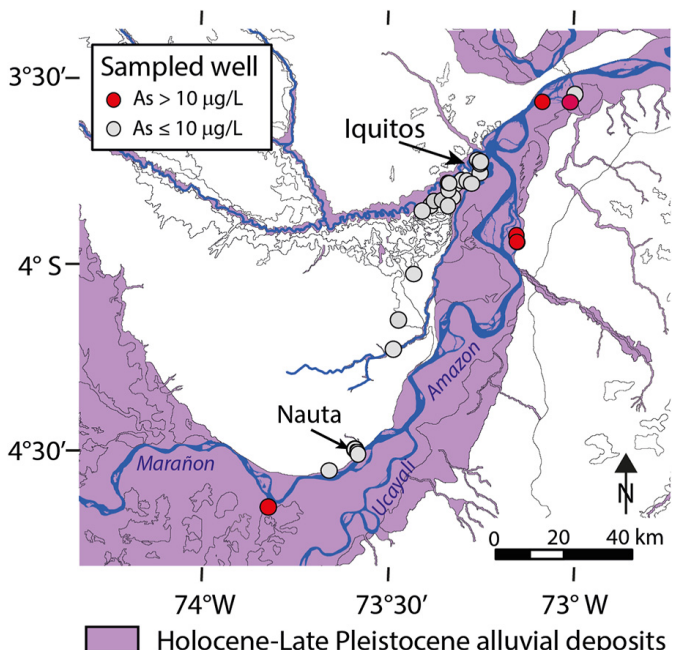

Figure 2. Indication of arsenic contaminated and non-contaminated wells around the city of Iquitos, in the Peruvian Western Amazon. Note that the wells where arsenic contamination was found are located in the floodplain of the Amazon river, i.e. on the recent alluvial deposits. (After de Meyer et al., 2017). sediment load. We used these observations to delineate the areas at risk of arsenic contaminated groundwater.

The effectiveness of the use of a small number of geological and hydrogeochemical parameters as spatial proxies to predict the regional distribution of high and low risk to arsenic concentrations has been demonstrated for As-affected basins in e.g. South-East Asia (Winkel et al., 2008). The Amazon Basin has hydrological and climatic conditions similar to Southeast Asia. We therefore tested the relevance of the parameters used in the model of Winkel et al. (2008), and explored the significance of other parameters, to provide a risk map for the Amazon region.

\section{CONCLUSION}

Our study provides first insights on the presence and distribution of arsenic in groundwater resources of the Amazon Basin. The high concentrations of arsenic encountered in groundwater along the populated floodplains of the Amazon river require urgent investigation on possible health effects.

\section{ACKNOWLEDGEMENTS}

The authors would like to thank Caroline Stengel, Thomas Rüttimann, Numa Pfenninger and the AuA laboratory at Eawag for chemical analysis of the samples. We are grateful to the well owners for access to their wells, and permission for sampling. The ETRASteam of PAHO in Lima and the DIRESA of Peru are sincerely thanked for their logistic support.

\section{REFERENCES}

Bretzler, A., Berg, M., Winkel, L., Amini, M., RodriguezLado, L., Sovann, C., Polya, D.A. \& Johnson, A. 2017. Geostatistical modelling of arsenic hazard in groundwater. In "Best Practice Guide on the Control of Arsenic in Drinking Water", Eds. Bhattacharya P., Polya D.A., Jovanovic D. IWA Publishing, London, UK. 153-160.

de Meyer, C.M.C., Rodríguez, J.M., Carpio, E.A., García, P.A., Stengel, C. \& Berg, M. 2017. Arsenic, manganese and aluminum contamination in groundwater resources of Western Amazonia (Peru). Sci. Total Environ. 607-608: 1437-1450.

Rodriguez-Lado, L., Sun, G., Berg, M., Zhang, Q., Xue, H., Zheng, Q. \& Johnson, C.A. 2013. Groundwater arsenic contamination throughout China. Science 341: 866-868.

WHO. 2011. Guidelines for Drinking-Water Quality. 4th ed. (Geneva).

Winkel, L., Berg, M., Amini, M., Hug, S.J. \& Johnson, A.C. 2008. Predicting groundwater arsenic contamination in Southeast Asia from surface parameters. Nat. Geosci. 1: 536-542. 